\title{
Introduction to The Politicisation of Social Europe
}

With the onslaught of the global financial and economic crisis, the European Union (EU) transformed - overnight and contre coeur - from a 'benign' project of single market expansion and currency integration into a highly contested political union. The Greek sovereign debt crisis of 2010 that almost brought down the euro fed back into political distrust among the leaders of the Member States, with the European Commission caught in the middle of the crossfire. With the financial crisis turning soon into a deep social crisis, the increasing intrusiveness of the EU into domestic decision-making, especially in those countries under economic adjustment programmes, pushed for a mobilisation of political parties in defence of national welfare states. The track-record of EU crisis management - overly attentive to debt sustainability and competitiveness-led growth strategy - festered a looming sense of social betrayal by the EU and heightened politicisation of EU affairs at the domestic level.

Many articles have been published that trace the evolution of 'Social Europe' after the Great Recession and the Eastern enlargement. The bulk of this literature has described the development of the social dimensions of the EU in negative terms by referring to the absorption, the displacement, the decline and the marginalisation of EU social policies. They shed light on different domains, including the legislative agenda (Garben, 2018; Kilpatrick, 2018), the coordination of national policies in the framework of the European Semester (Copeland and Daly, 2018; Dawson, 2018) and the financial support provided to Member States via the Multiannual Financial Framework (Avdikos and Chardas, 2016). Particular attention has been paid to the interaction between the economic and social dimension of the EU, and especially on the negative externalities of the former on the latter (Crespy and Menz, 2015; Degryse and Pochet, 2018). Several books, mostly edited volumes, have been published examining the EU response to the sovereign debt crisis and how this has affected welfare state reforms in the Member States. Among others, The Sovereign Debt Crisis, the EU and Welfare State Reform, edited by Caroline de la Porte and Elke Heins (2016); Social Policy and the Euro Crisis, edited by Amandine Crespy and Georg Menz (2015); A European Social Union after the Crisis, edited by Frank Vandenbroucke, Catherine Barnard and Geert De 
Baere (2017); Social Policy in the European Union 1999-2019: The Long and Winding Road, edited by Bart Vanhercke, Dalila Ghailani and Slavina Spasova, with Philippe Pochet (2020). While views differ on the extent to which the EU social dimension has evolved over the past decade, scholars agree that the centrality of social issues in the European public debate has progressively increased, exacerbating the conflicts between political actors on EU social and employment policy and mounting the dissensus towards the European integration process. The lack of political willingness, or the political incapacity, to propose and pursue a fully-fledged social agenda, on the one hand, and the absence of a legal and institutional framework that prevents or compensates the negative externalities of the economic integration process on the well-functioning and maintenance of flourishing national welfare states, on the other, has contributed to what can be called the 'politicisation of Social Europe'.

Despite the extensive discussion about the evolution of Social Europe over the last decade, the academic literature did not pay attention to the political debate underpinning the evolution of the EU social dimension. This is particularly surprising for at least three reasons.

Firstly, the literature on European politics both in the European Parliament (EP) and in the Council has flourished since the Great Recession. In 2018, for instance, a special issue was published that provides a comprehensive analysis of EU decision-making during the Eurozone crisis, based on a new 'EMU Positions' dataset elaborated in the framework of the Horizon 2020-funded project 'EMU choices'. The dataset includes information about the preferences and saliences of all 27 EU Member States (plus the UK) and key EU institutions, regarding 47 contested issues negotiated between 2010 and 2015. In 2017 a new comprehensive study by Richard Whitaker, Simon Hix and Galina Zapryanova, 'Understanding Members of the European Parliament: Four waves of the European Parliament Research Group MEP survey', was published presenting MEPs' views on topical issues concerning European integration. However, none of these studies looks at the specific conflict dynamics underpinning the European debate on social and employment issues and, overall, on EU social dimension.

Secondly, over the past ten years the EU has tried to regain social credibility, especially after the adoption of the European Pillar of Social Rights, relaunching its social agenda and progressively recalibrating the initial asymmetry between the social and economic sphere. This raises questions on whether and how the conflict constellations have changed over the past decade in order to allow such recalibration. Interestingly, the studies that claim the "progressive regression' of Social Europe (Streeck, 2018) or its displacement (Kilpatrick, 2018) largely consider the period up to the second Barroso Commission (2009-14) and ignore the most recent developments (from 2015 onwards). 
However, most recent publications, especially among legal scholars, point out an actual reverse of the previous trends and highlight a revitalisation of the EU social acquis both in the legislative arena (Bednarowicz, 2019; Chiaregato, 2020; Costamagna, 2019; Garben, 2019) and in the coordinative arena (Zeitlin and Vanhercke, 2018).

Thirdly, the Covid-19 pandemic turned out to be a stress-test for European welfare states. Member States intervened quickly providing liquidity, supporting income and employment, protecting the financial system and speeding up the economic recovery. A package of measures was rapidly agreed at the EU level, which included suspending common rules (like those on state aid) or the fiscal rules of the Stability and Growth Pact and three new financial instruments: a new conditionality light credit line from the European Stability Mechanism (ESM), a programme of low interest long-term loans, SURE, to help Member States finance short-term working schemes, and a financial support instrument for recovery and resilience, the Next Generation EU. In just a few months, the EU broke some of the taboos considered until that moment untouchable (the suspension of the fiscal framework, the creation of a common fiscal capacity, and the issuance of common EU debt) and put inclusivity, solidarity and cohesion at the centre of its recovery strategy.

Against this background, the objective of this book is twofold.

The first consists in filling the research gap in the literature on European politics, looking at the evolution of the political debate over the EU social dimension in the aftermath of the Euro crisis. Notably, the book focuses on the conflict dynamics that characterise the EU-level political debate on social and employment policies and their interplay with the EU economic governance during the Juncker Commission both in the EP and the Council of the EU. Therefore the first goal of the book is descriptive and aims to answer two main research questions: What influences the positioning of Members of the European Parliament on social and employment issues: European political group membership, national party group membership or national affiliation? And what shapes governments' positioning on social and employment issues: national interests or decision-makers' political affiliation?

The second objective of this book is to draw some lessons on the future of Social Europe. While looking at the evolution of the political debate over EU social integration in the past decade and comparing MEPs' and ministers' positioning on the same issue in two different moments in time and under two different Commissions, the book is able to advance hypotheses on how the juxtaposition and interdependence of political divides lead to the opening of windows of opportunity for policy change, or instead, turn into a political stalemate. In so doing, it aims to answer the following questions: Has the Great Recession indeed exposed the 'European social model' as the proverbial emperor without any clothes on? Have welfare retrenchment and labour 
market deregulation become the only games in town in terms of EU social policy engagement? Has there been no change in the European social agenda since the outbreak of the Great Recession? And, finally, as a consequence, should we expect the current Covid-19 crisis to reassert the welfare austerity imperative for the years ahead?

To answer these questions, this book adopts an innovative theoretical framework and proposes a new methodological approach to the study of European party politics. To start with the theoretical approach, the traditional literature on party politics and voting behaviour both in the EP and in the Council argues that the political conflict is mainly one- or bi-dimensional and tends to neglect or to diminish the territorial dimension of conflict. In so doing, however, scholars do not consider the recent multiple integration crises that have affected the $\mathrm{EU}$, which instead seem to suggest that a more complex conflict configuration at the EU level might have emerged in recent years. This is particularly true when it comes to the interaction between the economic and social dimension of the EU. By contrast, this book draws on Ferrera's 'clash syndrome' theory (Ferrera, 2017a) and argues that the post-crisis political debate on EU social and employment policies and their interplay with the European economic governance is characterised by four lines of conflict, which are not independent, but partly intersect and overlap with each other, creating policy dilemmas and mounting political turbulence. Such divides are of a functional and territorial nature and their combination mainly rests on four factors: the arena in which the debate takes place; the actors involved; the specific issue under discussion; and the rules of the legislative process. Notably, the Euro crisis has reinvigorated the traditional left versus right conflict over the degree and type of public intervention in the economy and has exacerbated the divide between advocates of 'more power to Brussels' vis-à-vis defenders of domestic models and practices. Besides the exacerbation of traditional lines of conflict, the crisis has brought out other political divides, with a specific territorial nature. Notably, in the case of the Economic and Monetary Union, a third divide emerged between supporters and opponents of fiscal stability and cross-national transfers. Similarly, in the case of labour and intra-EU mobility, a fourth divide emerged, notably around the issues of access to domestic welfare for other EU nationals and social dumping, which generates a further tension that exhibits a clear territorial connotation by separating high-wage/high-welfare countries from low-wage/low-welfare ones.

From a methodological point of view, the book adopts a qualitative approach. The research design is largely built on a criticism of the many quantitative studies (mainly based on the analysis of a large-n set of roll call votes) that have already been conducted on party politics in the EP and in the Council. Moving from the EP, the strategy adopted in this book to investigate the political conflict within the EP consists of carrying out qualitative anal- 
ysis of the amendments tabled in the parliamentary committee in charge of a certain report. While scholars who have studied the parliamentary activity in the EP committees have mostly focused on the topic of membership of EP committees and the assignment of leadership positions and rapporteurship, few studies have researched the extent to which national parties use the committees' system to further their policy goals, and no research has been conducted on the amendments tabled by MEPs in EP committees, which are, however, a unique source of information to investigate political positioning in the EP. The empirical findings were triangulated with elite and expert semi-structured interviews with key decision-makers involved in the policy-making process. Moving to the Council, this book relies on a combination of multiple, complementary sources of information to unveil the national governments' position on the policy proposals under discussion. Firstly, it qualitatively analyses the records of the public sessions of the Council's meetings. Notably, the records of the ministers' or their delegates' speeches during the debate are transcribed and classified according to their positioning vis-à-vis the proposed text of the Commission or the compromise text created by the presidency. The second source of information we use to trace the positioning of Member States in the Council is - where available - reasoned opinions, sent by national parliaments when they deem that a Commission's proposal violates the principle of subsidiarity, or national position papers. Finally, the empirical findings are triangulated with elite and expert semi-structured interviews with key decision-makers involved in the policy-making process.

To empirically investigate the positioning of deputies in the European Parliament and ministers in the Council and to test the clash syndrome theory, this book proposes a collection of four case studies that focus on four initiatives debated under the Juncker Commission. The case studies' analysis is completed with an historical analysis of the evolution of Social Europe and its interplay with the European Economic governance from the creation of the EMU up to the Juncker Commission. Finally, a detailed analysis of the EU response to the Covid-19 crisis and its impact on the national welfare states is provided.

This book is composed of seven chapters.

Chapter 1 presents the research design. It illustrates the puzzle and the object of the research and offers an overview of the literature on party politics and voting behaviour in the European Parliament and in the Council, while shedding light on the substantial and methodological limitations of scholars in this area. It then introduces the theoretical framework and the hypotheses that derive from it. Accordingly, Chapter 1 presents the selected case studies and the research strategy adopted to investigate them.

Chapter 2, co-authored with Anton Hemerijck, offers a bird's-eye view on the evolution of the EU social agenda in the aftermath of the Great Recession. 
It provides an empirical reconstruction of the EU social and employment agenda in the past decade, by looking at the evolution of the EU social legislation (directives, regulations and recommendations) and the interaction between the EU economic governance and national employment and social policies (mainly via the European Central Bank and the European Semester). Special attention is also payed to changes in the ideational framework that accompanied the adoption of measures. Three different periods of the EU social agenda in the wake of the global financial crash are identified: an initial 'conservative reflex' (2008-12), characterised by the subordination of the social and employment priorities to the imperative of fiscal sustainability, budgetary stability and competitiveness. A moment of 'social crisis discernment' (2012-14) in which the EU social dimension is recognised as important but remained subsumed under a benign logic of social policy as a productive factor which lacked political ownership outside the Commission. Finally, the third period (2015-19) is characterised by a revitalisation in EU social legislation, a relaunch of the EU social dialogue, further socialisation of the European Semester and a more flexible interpretation of the Stability and Growth Pact parameters.

Chapter 3 first briefly introduces the European Pillar of Social Rights (EPSR), providing the reader who is not familiar with it the necessary information on the genesis and implementation of this initiative. It then analyses the conflict dynamics in the European Parliament's debate on the EPSR. Firstly, it presents the draft report prepared by MEP Maria João Rodrigues, which constitutes the basis of the debate in the EP. It then analyses in detail the amendments tabled in the Employment and Social Affairs (EMPL) committee, with the aim to identify the policy issues on which European deputies are divided, and consequently where tensions emerge. Position papers of parliamentary groups and final roll call vote are analysed both within the EMPL committee and in the plenary session. Overall, the chapter provides empirical evidence of the existence of all four lines of conflict, which results from the combination of vertical and horizontal forms of Euroscepticism.

Chapter 4 focuses on the political debate around the Posting of Workers Directive (PWD). It first introduces the controversial issues at stake with respect to posting of workers, with the aim of identifying possible dimensions of conflict. It then explores and compares the political conditions that led to the failure of the Monti II regulation in 2012, the adoption of the Enforcement Directive in 2014 and the revision of the PWD in 2018. A complex interplay of multiple lines of conflict characterises the debate over the revision of the PWD. However, the combination of such divides varies significantly in the Parliament and the Council. While in the former, the functional divide between left and right overlaps and partially trumps the territorial cleavage between high-welfare and low-welfare Member States, in the Council, the geographical 
divide prevails over the left-right split. Both in the Council and the Parliament, a third divide emerges: between advocates of further EU integration and supporters of national social sovereignty.

Chapter 5 reconstructs the post-crisis debate over the possibility of establishing a European Unemployment Benefit Scheme (EUBS). It first introduces the controversial issues at stake with respect to the creation of a EUBS, with the aim of identifying possible dimensions of conflict. It then reconstructs the debate on EUBS during the Barroso Commission and then focuses on the Juncker mandate. In the second case, the focus is on the European Parliament report on a budgetary capacity for the EU and the debate in the Council on the Five Presidents' Report and the Commission's Reflection Paper on deepening the EMU. This chapter provides empirical evidence of the interplay of three main divides that characterise the debate on an EU fiscal capacity. As in the case of the PWD, the combination of these divides varies significantly between the Parliament and the Council. In the Parliament, the left vs right conflict intersects and partially trumps the territorial divide between supporters and opponents of fiscal transfer and cross-national redistribution, while in the Council, the latter prevails over the former.

Chapter 6 analyses the evolution of the social dimension of the European Semester, by focusing on how politics played a decisive role in reorienting the social policy prescriptions addressed to Member States. Notably, the chapter investigates the 'possibility spaces' that have been opened up by the introduction of the Social Pillar and have led to a further socialisation of the Semester. While focusing on how the European Semester dealt with national social policies in the period 2011-19, this chapter highlights the role of politics and, especially, the interaction between the political and expertise agentic factors within the Semester.

The final chapter recalls the main findings of the book and analyses them in light of the 'clash syndrome' theory and the hypotheses advanced in Chapter 1 and against the evolution of the EU social dimension presented in Chapter 2. Against this background, this chapter focuses on the agenda of the new Commission led by Ursula von der Leyen and analyses the EU response to the pandemic crisis. Finally, it concludes with some considerations on the future of Social Europe and the possible scenario that might emerge in the years to come. 